\title{
Energy consumption, Income and Price Interactions in Saudi Arabian Economy: A Vector Autoregression Analysis
}

\author{
Mohamed Abbas Ibrahim ${ }^{1}$
}

\begin{abstract}
This paper presents an empirical analysis of the interactions among energy consumption, real income and energy price in Saudi Arabia using annual data from 1982 to 2007. We analyzed the dynamic interaction by applying widely used time series analysis techniques such as unit root tests, Vector Autoregressive model, Granger causality tests, impulse response functions and the forecast error variance decompositions. Results show that real income and energy consumption are clearly Granger causal for energy price, and there is bidirectional causality between energy consumption and income. On the other hand energy price isn't a Granger causal for either energy consumption or real income. Thus, real income can play an important role in policy that targeting to enhance the energy efficiency to save energy in Saudi Arabia.
\end{abstract}

JEL classification numbers: Q43, C32

Keywords: Energy Consumption, Vector Autoregressive (VAR) Model, Granger Causality, Impulse Response

${ }^{1}$ College of Administrative Sciences and Humanities, Majmaah University, Saudi Arabia e-mail: m.a.ibrahim@mu.edu.sa \& albarsi2020@gmail.com

Article Info: Revised: June 25, 2011. Published online: October 31, 2011 


\section{Introduction}

Energy demand has been analyzed extensively on a national and international basis since the early 1980s, initially motivated by concerns about the security of energy supply in view of the oil price shocks of 1973 and 1979. The primary exercise in most energy analysis is to determine income and price elasticities of energy consumption at all or electricity consumption in other cases, so that meaningful forecasts or policy simulations can be performed. These studies typically analyze the long-term and short-term impact of energy prices and GDP on aggregate consumption or consumption per capita of one or more fuels, in individual sectors or over the whole economy.

Over the last two decades, a major challenge has been to explore the time series properties of the examined variables in order to conduct meaningful statistical tests and inferences. Since the seminal work of Engle and Granger (1987), Phillips and Durlauf (1986) and others, it became clear that inferences from autoregressive equations are only meaningful if the variables involved are stationary, i.e. fluctuate stochastically with constant unconditional means and variances. As a result, unit root tests became commonplace and cointegration methods, such as the Engle-Granger (1987) or the Johansen $(1988,1991)$ approach among others, were employed in order to test for the existence of stationary long-run relationships among the non-stationary variables that would allow the implementation of standard regression methods.

In line with several recent approaches (for a summary see e.g. Hondroyiannis, 2004), our purpose was to analyze energy consumption in relation to appropriate economic activity or income variables and energy prices. Climate changes are used often in the literature in order to account for seasonal variations in the energy demand, mostly for the heating of the domestic sector. However, this variable loses its explanatory power in aggregate demand studies due to its different influence to various sectors. Especially in Saudi Arabia, the industrial sector is not influenced by the temperature change; however, it is the biggest consumer of 
energy in the country. Following the majority of recent literature in time series analysis of energy data, we first examine the time series properties of the underlying energy, income and price data. Based on the results of unit root tests for the variables involved, we proceed in formulating and estimating an appropriate Vector Autoregressive (VAR) model.

After an overview of the Saudi Arabian energy sector, the paper continues with a description of the data that were collected and then the unit root tests were performed. In view of the results of these tests, a VAR Model was estimated, which allows one to draw conclusions about the impacts of income and prices on energy consumption, as well as on issues of Granger causality among the variables, impulse response function and variance decomposition.

\section{The energy sector in Saudi Arabia}

Saudi Arabia was the world's largest producer and exporter of total petroleum liquids in 2010, and the world's second largest crude oil producer behind Russia. Saudi Arabian economy remains heavily dependent on crude oil. Oil export revenues have accounted for 80-90 percent of total Saudi revenues and above 40 percent of the country's gross domestic product (GDP). Saudi Arabia is the largest consumer of petroleum in the Middle East, particularly in the area of transportation fuels and direct burn for power generation. Domestic consumption growth has been spurred by the economic boom due to historically high oil prices and large fuel subsidies. In 2008, Saudi Arabia was the 15th largest consumer of total primary energy, of which almost 60 percent was petroleum-based and the rest natural gas (http://www.eia.doe.gov).

As can be shown in Table 1 and Figure 1, total energy consumption is growing steadily and very rapidly, at an average growth rate of 8.7 percent/year during 1982-2007. In 2008, the National Energy Efficiency Program (NEEP) defined the objectives that can cut down the energy consumption growth, including energy 
audit services and industry support, efficient use of oil and gas, energy efficiency labels and standards for appliances, construction codes and technical management and training (http://www.neep.org.sa).

Table 1: Energy Production and Consumption and its average growth rates in Saudi Arabia 1982-2007

\begin{tabular}{cccccc}
\hline \multicolumn{2}{c}{$\begin{array}{c}\text { Energy Production } \\
\text { (thousand kt of oil equivalent) }\end{array}$} & \multicolumn{3}{c}{$\begin{array}{c}\text { Energy Consumption } \\
\text { (thousand kt of oil equivalent) }\end{array}$} \\
\hline 1982 & 2007 & $\begin{array}{c}\text { Average Growth } \\
\text { Rate (\%) }\end{array}$ & 1982 & 2007 & $\begin{array}{c}\text { Average Growth } \\
\text { Rate (\%) }\end{array}$ \\
\hline \multicolumn{7}{c}{} & & & & \\
\hline 361.339 & 551.299 & 2.1 & 47.32 & 150.326 & 8.7 \\
\hline
\end{tabular}

Source: World Bank (http://data.worldbank.org/indicator/).

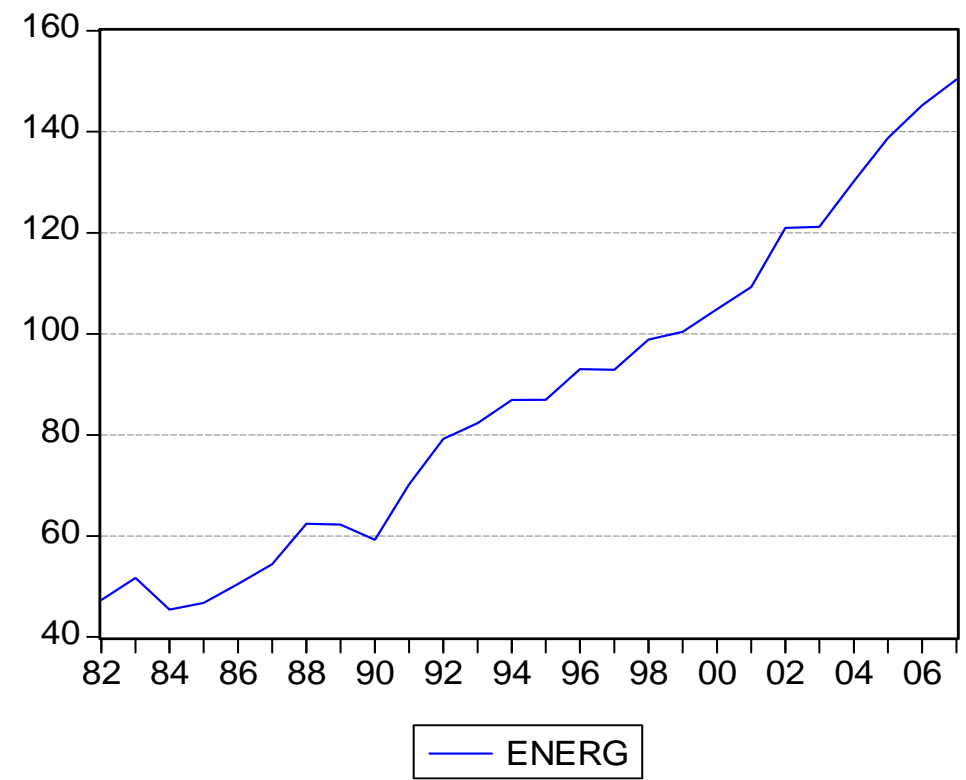

Figure 1: Energy consumption in Saudi Arabia (thousand kilo oil equivalent) 1982-2007

\section{Methodology and Choice of Variables}

This paper employs the Vector Autoregressive (VAR) technique to test energy 
consumption, income and energy price interactions in Saudi Arabian economy. This technique was presented by Sims (1980) as a means of overcoming the limitations of the traditional structural approach in modeling macroeconomic variables.

Charmeza and Deadman (1997) mentioned the simultaneity bias in a simultaneous equation model caused by the possible existence of a feedback relationship between one or more of the independent variables on one hand and the dependent variable on the other as one of those limitations. This results in biased coefficients and standard errors estimated by OLS. Charemza and Deadman (1997) also stated that the traditional multi-equation modeling has been criticized for two main assumptions namely (i) the zero restriction assumptions imposed on some variables as a solution for the identification problem, and (ii) A priori division of variables into exogenous and endogenous variables.

Both of those assumptions are often based mostly on the econometrician's judgment rather than economic theory justifications.

The VAR model on the other hand is a nonstructural approach in the sense that no particular relationships are imposed on the variables based on economic theory. Thus, the only prior information required for analysis is the set of interacting variables within the economic system and the sufficient number of lags that could capture the interrelationships among them and eliminate autocorrelation in the error terms (Pindyck \& Rubinfeld, 1998). In the VAR model, all variables are dealt with symmetrically as endogenous variables and every endogenous variable is a function of the lagged values of all endogenous variables which avoids the simultaneity bias problem (Moursi \& El-Mossallamy, 2003). Moreover, the unrestricted VAR models can easily be estimated using the OLS method, because the right hand side consists of similar predetermined variables in each equation, as well as serially uncorrelated errors with constant variances (Pindyck \& Rubinfeld, 1998).

In the present study we will estimate a VAR model with three variables; energy 
consumption, real GDP and energy prices.

\section{Data and unit root tests}

\subsection{Data}

The time series data used in the present analysis is in annual frequency and spans the period from 1982 to 2007. Energy consumption has been taken from World Bank Development Indicator (http://data.worldbank.org/indicator/). Income is proxied by real GDP (GDP deflated by GDP deflator 1999=100); energy price is proxied by energy consumer price index $(1999=100)$ has been obtained from the annual report of Saudi Arabian Monetary Agency (SAMA) (2010). These data can be seen in Table (A.1) in Appendix (A).

In the absence of appropriate seasonal economic indicators for Saudi Arabia, the analysis had to rely on annual data. Hence the analysis that follows is as detailed as the available information allows.

\subsection{Unit root tests}

Table 2 reports the results of Augmented Dickey-Fuller (ADF), Phillips-Perron (PP), and Kwiatkowski, Phillips, Schmidt and Shin (KPSS) unit root tests for all variables; LENERG, LRGDP and CPIENERG, where these variables represents energy consumption, real GDP and energy consumer price index respectively. It is necessary to note here that unit root test results should be treated with caution. For one thing, the size and power of unit root tests is typically low because it is difficult to distinguish between stationary and non-stationary processes in finite samples (Harris and Sollis 2003), and there is a switch in the distribution function of the test statistics as one or more roots of the data generating process approach unity (Cavanagh, 1995; Pesaran, 1997). Moreover, the sample size (with a maximum of 26 observations) is quite small. 
Table 2: Unit root tests

\begin{tabular}{|c|c|c|c|c|c|}
\hline & & & $\mathrm{ADF}$ & $\mathrm{PP}$ & KPSS \\
\hline \multirow{2}{*}{ LENERG } & \multirow{2}{*}{ Level } & $\mathrm{C}$ & -1.760882 & 3.749372 & $0.776535 a$ \\
\hline & & $\mathrm{C}, \mathrm{T}$ & $-5.464770 a$ & $-5.026676 a$ & 0.084745 \\
\hline \multirow{2}{*}{ LRGDP } & \multirow{2}{*}{ Level } & $\mathrm{C}$ & 1.064399 & 0.626559 & $0.605142 b$ \\
\hline & & $\mathrm{C}, \mathrm{T}$ & $-3.698860 b$ & -2.579031 & c0.121657 \\
\hline \multirow{2}{*}{ LCPINERG } & \multirow{2}{*}{ Level } & $\mathrm{C}$ & -1.993355 & -1.224529 & 0.162969 \\
\hline & & $\mathrm{C}, \mathrm{T}$ & -1.577493 & -0.580021 & $0.145239 c$ \\
\hline
\end{tabular}

Notes: ADF-Dickey DA, Fuller WA., (1979) unit root test with the Ho: Variables are I (1);

PP- Phillips and Perron (1988) unit root test with the Ho: Variables are I (1); KPSS-

Kwiatkowski, Phillips, Schmidt and Shin (1992) unit root test with Ho: variables are I(0); a, b and c indicate significance at the $1 \%, 5 \%$ and $10 \%$ levels, respectively. (C, T) indicate that the test executed with intercept, trend respectively.

While ADF test confirm the existence of a unit root in level for one variable and PP test confirm the existence of a unit root in level for two variables, KPSS confirm the stationarity of all variables. So, we can consider the conclusion that the energy use, real GDP and energy consumer price data of Saudi Arabia exhibit stationary properties seems to be valid.

\section{$5 \quad$ VAR analysis}

\subsection{Determination the lag order of the VAR}

Since all the variables according to KPSS test are integrated in the level (I(0)), we can model them as a VAR in levels. In order to construct the VAR, we need to determine the lag order of the VAR, i.e., the optimum number of lags. The optimum lag length can be determined either by using the Akaike Information Criteria (AIC), the Schwartz Information Criteria (SC), Final Prediction Error (FPE), Likelihood Ratio (LR) or by Hannan-Quinn information criterion (HQ) Tests. Table 3 gives the results of all these tests for the lag lengths of a VAR of the three variables. All tests show that the optimal lag order of the VAR is three, 
with the exception of AIC test where the optimal lag order according to it is four. This implies that the VAR will have a lag length of 3.

Table 3: Test Statistics and Choice Criteria for Selecting the Order of the VAR Model

\begin{tabular}{ccccccc}
\hline Lag & LogL & LR & FPE & AIC & SC & HQ \\
\hline \multicolumn{7}{c}{} \\
\hline 0 & 56.65524 & NA & $2.74 \mathrm{e}-06$ & -4.292419 & -4.146154 & -4.251851 \\
1 & 144.1021 & 146.9108 & $5.21 \mathrm{e}-09$ & -10.56817 & -9.983110 & -10.40590 \\
2 & 164.3665 & 29.18070 & $2.20 \mathrm{e}-09$ & -11.46932 & -10.44546 & -11.18535 \\
3 & 181.4827 & $20.53945^{*}$ & $1.26 \mathrm{e}-09^{*}$ & -12.11862 & $-10.65597^{*}$ & $-11.71294^{*}$ \\
4 & 191.0871 & 9.220198 & $1.46 \mathrm{e}-09$ & $-12.16697^{*}$ & -10.26552 & -11.63959 \\
\hline * indicates lag order selected by the criterion & & & \\
LR: sequential modified LR test statistic (each test at 5\% level) & & \\
FPE: Final prediction error \\
AIC: Akaike information criterion \\
SC: Schwarz information criterion \\
HQ: Hannan-Quinn information criterion
\end{tabular}

\subsection{Granger Causality}

We have adopted the VAR Granger Causality/Block Exogeneity Wald Tests to examine the causal relationship among the variables. Under this system, an endogenous variable can be treated as exogenous. We used the chi-square (Wald) statistics to test the joint significance of each of the other lagged endogenous variables in each equation of the model and also for joint significance of all other lagged endogenous variables in each equation of the model. Results are reported in Table 4. A chi-square test statistics of 22.58 for LRGDP with reference to LENERG represents the hypothesis that lagged coefficients of LRGDP in the regression equation of LENERG are equal to zero. Similarly, the lagged coefficients of LCPIENERG as well as block of all coefficients in the regression equation of LENERG are equal to zero. Results indicate that, LRGDP is Granger Causal for LENERG at level 1\% of significance, while LCPIENERG doesn't granger causal for LENERG. Also, all the variables are Granger Causal for 
LENERG at the $1 \%$ significance level. The test results for LENERG equation however indicate that null hypothesis cannot be rejected for individual lagged coefficient for LCPIENERG, this suggests that LENERG is not influenced by LCPIENERG. But all the variables are Granger Causal for LENERG at the 1\% significance level. The null hypothesis of block exogeneity is rejected for all equations in the model.

Table 4: VAR Granger Causality/Block Exogeneity Wald Tests Results

\begin{tabular}{ccccc}
\hline $\begin{array}{c}\text { Dependent } \\
\text { Variable }\end{array}$ & Excluded & $\begin{array}{c}\text { Chi-Square } \\
\text { Statistics }\end{array}$ & $\begin{array}{c}\text { Degrees of } \\
\text { Freedom }\end{array}$ & P value \\
\hline \multirow{3}{*}{ LENERG } & LRGDP & 22.58023 & 3 & 0.0000 \\
& LCPIENERG & 3.955986 & 3 & 0.2663 \\
& ALL & 27.06276 & 6 & 0.0001 \\
LRGDP & LENERG & 19.89813 & 3 & 0.0002 \\
& LCPIENERG & 3.690783 & 3 & 0.2968 \\
& ALL & 52.01277 & 6 & 0.0000 \\
LCPIENERG & LENERG & 43.29046 & 3 & 0.0000 \\
& LRGDP & 24.10936 & 3 & 0.0000 \\
& ALL & 70.22929 & 6 & 0.0000 \\
\hline
\end{tabular}

The only evidence of bi-directional causality is observed between LENERG and LRGDP which implies that both energy consumption and real income are influenced by each other. Uni-directional causality is observed from LENERG and LRGDP to LCPIENERG.

\subsection{The Estimation Results of the VAR Model}

The VAR model for the three I(0) variables; energy consumption (LENERG), the real GDP (RGDP) and energy consumer price index (CPIENERG) can be set up as the following system of equations:

$$
\text { LENERG }_{t}=\alpha_{0}+\alpha_{i 1} \sum_{i=1}^{3} L E N E R G_{t-i}+\alpha_{2 i} \sum_{i=1}^{3} L R G D P_{t-i}+\alpha_{3 i} \sum_{i=1}^{3} C P I E N E R G_{t-i}+u_{1 t}
$$




$$
\begin{aligned}
& \operatorname{LRGDP}_{t}=\beta_{0}+\beta_{1 i} \sum_{i=1}^{3} \operatorname{LENERG}_{t-i}+\beta_{2 i} \sum_{i=1}^{3} L R G D P_{t-i}+\beta_{3 i} \sum_{i=1}^{3} \operatorname{CPIENERG}_{t-i}+u_{2 t} \\
& \text { LENERG }_{t}=\theta_{0}+\theta_{1 i} \sum_{i=1}^{3} \operatorname{LENERG}_{t-i}+\theta_{2 i} \sum_{i=1}^{3} \operatorname{LRGDP}_{t-i}+\theta_{3 i} \sum_{i=1}^{3} \operatorname{CPIENERG}_{t-i}+u_{3 t}
\end{aligned}
$$

The VAR model incorporates three endogenous variables in their levels plus the intercept term using annual data over the period 1982-2007. All these variables are in the natural logarithmic forms. Table 5 illustrates the summary of the VAR model estimation results, whereas the detailed results are shown in Table (A.2) in Appendix (A).

The VAR estimated results support the Granger causality results of block exogeneity Wald tests for all equations in the model. Considering the targeted variable (LENERG), the coefficient of determination R2 indicates that the incorporated variables capture almost $99 \%$ of the variations in energy consumption. To evaluate VAR model estimates, we made econometric tests of the series distribution (Figure B.1), autocorrelations (Table A.3 and Figure B.2) and normality (Table A.4) of residuals and all can be seen in the Appendix. The results of tests are no autocorrelation and normality existing in the residual series of the VAR model. So, the results seem to be satisfactory and correct.

\section{The Impulse Response Functions (IRFs)}

Impulse response functions (IRFs) show the dynamic behavior of a variable as given by its time path in response to exogenous random shocks given to this and other variables. This makes it possible to compare the predictions of the model with those of economic theory. Figure (2) illustrates the impulse response functions (IRFs) of the VAR model for a period of 10 years. Each panel in the figure depicts the dynamic effect of a one standard deviation innovation on each of the three variables. 
Table 5: Vector Autoregression Estimates

Vector Autoregression Estimates

Sample (adjusted): 19822007

Included observations: 26 after adjustments

Standard errors in ( ) \& t-statistics in [ ]

\begin{tabular}{cccc}
\hline & LENERG & LRGDP & LCPIENERG \\
\hline LENERG(-1) & $0.363674 \mathrm{c}$ & -0.102858 & $-0.291024 \mathrm{a}$ \\
LENERG(-2) & -0.141991 & -0.023607 & 0.107456 \\
LENERG(-3) & $0.371878 \mathrm{~b}$ & $0.205578 \mathrm{~b}$ & -0.066523 \\
LRGDP(-1) & $0.601748 \mathrm{~b}$ & $0.839838 \mathrm{a}$ & -0.082209 \\
LRGDP(-2) & $0.660179 \mathrm{~b}$ & $0.333423 \mathrm{c}$ & $0.261415 \mathrm{~b}$ \\
LRGDP(-3) & -0.505500 & -0.282498 & $0.526108 \mathrm{a}$ \\
LCPIENERG(-1) & $-0.817573 \mathrm{c}$ & 0.086580 & $0.778922 \mathrm{c}$ \\
LCPIENERG(-2) & 0.762009 & -0.467845 & -0.244940 \\
LCPIENERG(-3) & -0.174987 & $0.306783 \mathrm{c}$ & -0.107979 \\
\multicolumn{1}{c}{ C } & 1.633394 & 0.216423 & $2.554545 \mathrm{a}$ \\
\hline R-squared & 0.990732 & 0.987796 & 0.987710 \\
Adj. R-squared & 0.985518 & 0.980931 & 0.980797 \\
Sum sq. resids & 0.033411 & 0.012948 & 0.004657 \\
S.E. equation & 0.045697 & 0.028447 & 0.017060 \\
F-statistic & 190.0363 & 143.8886 & 142.8734 \\
Log likelihood & 49.64825 & 61.97153 & 75.26504 \\
Akaike AIC & -3.049865 & -3.997810 & -5.020387 \\
Schwarz SC & -2.565982 & -3.513927 & -4.536504 \\
Mean dependent & 4.411350 & 1.703790 & 4.587533 \\
S.D. dependent & 0.379730 & 0.206002 & 0.123112 \\
Determinant resid covariance (dof adj.) & $4.34 \mathrm{E}-10$ & \\
Determinant resid covariance & $1.01 \mathrm{E}-10$ & \\
Log likelihood & & 188.5036 & \\
Akaike information criterion & -12.19259 & \\
Schwarz criterion & & -10.74094 & \\
\hline Notes: b and ind & & \\
\hline
\end{tabular}

Notes: a, b and c indicate significance at the $1 \%, 5 \%$ and $10 \%$ levels, respectively

Generalized impulse response analysis, along with Granger causality test, seems to confirm that real income has significant impact on energy consumption and vice versa. On another hand, energy price has insignificant impact either on energy consumption or real income. And both of energy consumption and real income has significant impacts on energy price. 
Response to Cholesky One S.D. Innovations \pm 2 S.E.
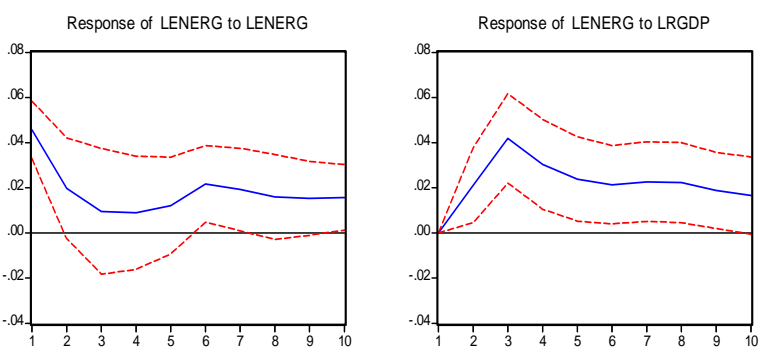

Response of LENERG to LCPIENERG
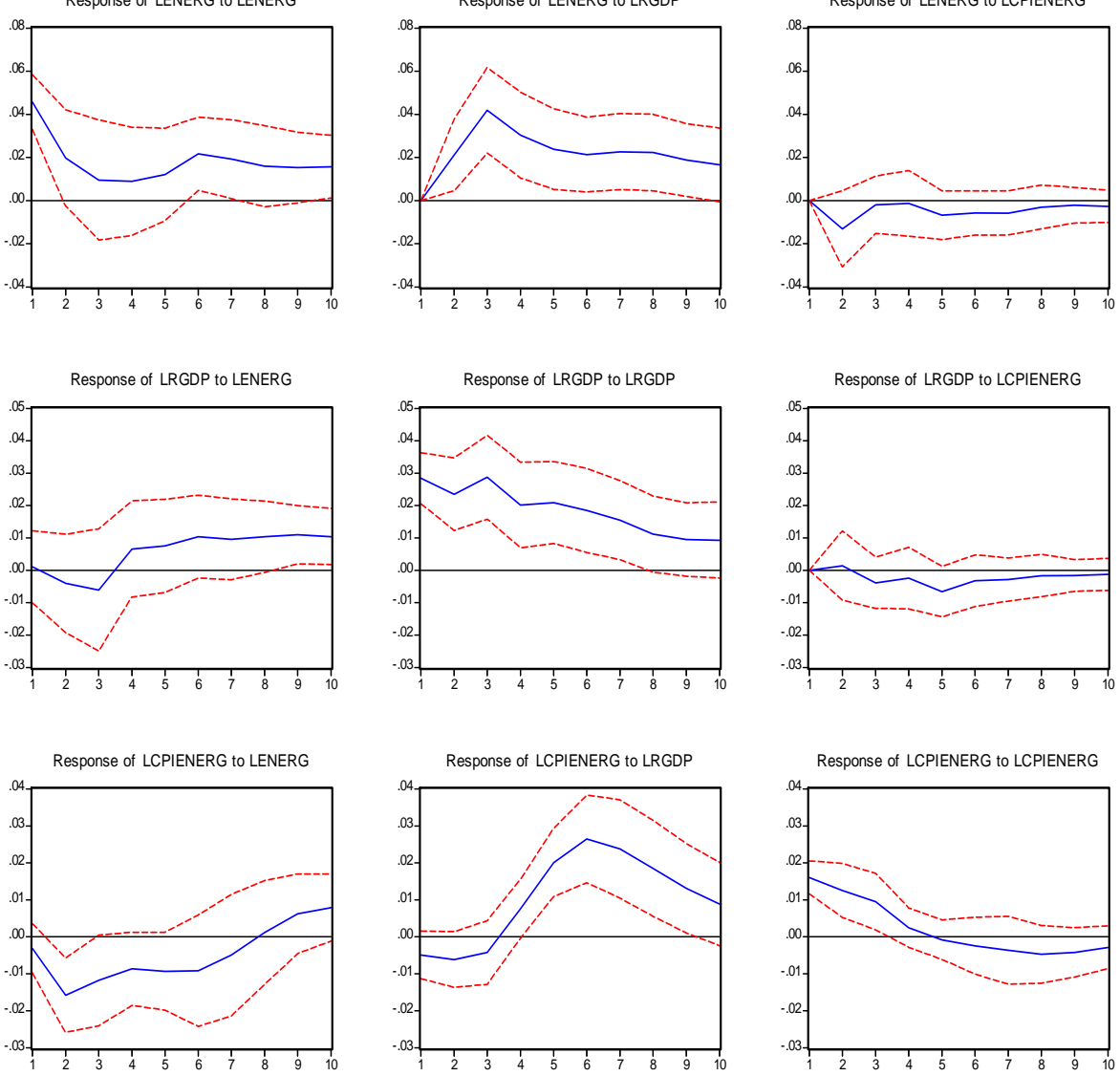

Figure 2: The Impulse Response Functions (IRFs)

\section{The Forecast Error Variance Decompositions (VDCs)}

The forecast error variance decomposition for each variable reveals the proportion of the movement in this variable due to its own shocks versus the shocks in other variables. Hence, while the IRFs show the direction of the dynamic response of the variables to different innovations, the VDCs provide the magnitude of the response to the shocks. Results are reported in table (6) at various forecast horizons over a period of 10 years. Table (6) gives the forecast error variance decomposition for the 3 variables included in the estimated VAR. 
Table 6: The VAR model Forecast Error Variance Decompositions

Variance Decomposition of LENERG:

\begin{tabular}{ccccc}
\hline Period & S.E. & LENERG & LRGDP & LCPIENERG \\
\hline & & & & \\
\hline 1 & 0.045697 & 100.0000 & 0.000000 & 0.000000 \\
2 & 0.055659 & 80.05743 & 14.39026 & 5.552315 \\
3 & 0.070312 & 51.99371 & 44.45195 & 3.554338 \\
4 & 0.077075 & 44.59402 & 52.41828 & 2.987704 \\
5 & 0.081864 & 41.71329 & 54.95552 & 3.331189 \\
6 & 0.087529 & 42.63259 & 54.02424 & 3.343170 \\
7 & 0.092624 & 42.38131 & 54.24371 & 3.374978 \\
8 & 0.096624 & 41.64856 & 55.15214 & 3.199297 \\
9 & 0.099625 & 41.52634 & 55.41734 & 3.056321 \\
10 & 0.102243 & 41.79158 & 55.23709 & 2.971330 \\
\hline
\end{tabular}

Variance Decomposition of LRGDP:

\begin{tabular}{ccccc}
\hline Period & S.E. & LENERG & LRGDP & LCPIENERG \\
\hline & & & & \\
\hline 1 & 0.028447 & 0.136976 & 99.86302 & 0.000000 \\
2 & 0.037118 & 1.292011 & 98.56798 & 0.140006 \\
3 & 0.047514 & 2.440762 & 96.79740 & 0.761841 \\
4 & 0.052083 & 3.627955 & 95.52346 & 0.848585 \\
5 & 0.056996 & 4.758546 & 93.17665 & 2.064799 \\
6 & 0.060885 & 7.055991 & 90.85095 & 2.093059 \\
7 & 0.063601 & 8.716296 & 89.16338 & 2.120327 \\
8 & 0.065416 & 10.73974 & 87.18900 & 2.071251 \\
9 & 0.067014 & 12.89177 & 85.07529 & 2.032940 \\
10 & 0.068461 & 14.66070 & 83.35607 & 1.983230 \\
\hline
\end{tabular}

Variance Decomposition of LCPIENERG:

\begin{tabular}{ccccc}
\hline Period & S.E. & LENERG & LRGDP & LCPIENERG \\
\hline & & & & \\
\hline 1 & 0.017060 & 3.331450 & 8.255805 & 88.41275 \\
2 & 0.027112 & 35.32780 & 8.423340 & 56.24886 \\
3 & 0.031344 & 40.58836 & 8.127824 & 51.28382 \\
4 & 0.033474 & 42.28991 & 12.21137 & 45.49872 \\
5 & 0.040132 & 34.81427 & 33.49117 & 31.69457 \\
6 & 0.048991 & 26.86734 & 51.61485 & 21.51781 \\
7 & 0.054791 & 22.29951 & 60.04641 & 17.65408 \\
8 & 0.058035 & 19.91723 & 63.67312 & 16.40965 \\
9 & 0.059970 & 19.72557 & 64.41091 & 15.86352 \\
10 & 0.061193 & 20.60894 & 63.93826 & 15.45280
\end{tabular}


However, since LENERG is the target variable, the discussion will focus on analyzing its variance decomposition. The main source of variation in the energy consumption is its own shocks with a percentage of $100 \%$ and $80.06 \%$ of the forecast error variance in the first and second period of forecast horizon respectively, that declines to reach a value of $41.8 \%$ in the tenth year.

The change in the RGDP represents the second source of variation in LENERG with a percentage of $14.39 \%$ in the second year forecast horizon. This percentage increases considerably to reach $55.24 \%$ at the end of the forecast horizon. Finally, the contribution of LCPIENERG remains fairly stable over the whole forecast horizon.

The main source of variation in the real income is its own shocks with a percentage of $99.8 \%$ of the forecast error variance in the first period of forecast horizon, that declines to reach a value of $83.3 \%$ in the tenth year.

The change in the LENERG represents the second source of variation in LRGDP with a percentage begins with $0.13 \%$ in the first year forecast horizon. This percentage increases considerably to reach $14.66 \%$ at the end of the forecast horizon. Finally, the contribution of LCPIENERG remains fairly stable over the whole forecast horizon.

However, The main source of variation in the energy prices is its own shocks with a percentage of $88.4 \%$ of the forecast error variance in the first period of forecast horizon, that declines sharply along the period to reach a value of $15.45 \%$ in the tenth year.

During the first four years of period horizon, the main source of variation in energy prices is caused by the energy consumption which reaches to highest value $42 \%$ at the fourth period, after that the real GDP becomes the main source of variation which reaches to $63.94 \%$ at the tenth year. 


\section{Conclusions}

This paper has presented an empirical analysis of the interactions among energy consumption, real income and energy price in Saudi Arabia using annual data from 1982 to 2007 . We analyzed the dynamic interaction by applying widely used time series analysis techniques such as unit root tests, Vector Autoregressive model, Granger causality tests, impulse response functions and the forecast error variance decompositions. Results show that real income and energy consumption are clearly Granger causal for energy price, and there is bidirectional causality between energy consumption and income. On the other hand energy price isn't a Granger causal for either energy consumption or real income. Thus, real income can play an important role in policy that targeting to enhance the energy efficiency to save energy in Saudi Arabia.

Despite the quite small sample size, which poses limitations on the analysis, results reported here have passed several specification tests, so that they can be used for forecasts of energy consumption, real income and energy price in the future.

\section{References}

[1] C.L. Cavanagh, G. Elliott, J.H. Stock, Inference in models with nearly integrated regressors, Econometric Theory, 11, (1995), 1131-1147.

[2] W. Charemza and D. Deadman, New directions in Econometric practice: General to specific modeling, Cointegration and Vector Autoregressio,(2nd edition), Cheltenham: Edward Elgar, 1997.

[3] D.A. Dickey and W.A. Fuller, Estimators for autoregressive time series with a unit root, J. of the American Statistical Association, 74, (1979), 427-431.

[4] R.F. Engle and C.W.J. Granger, Cointegration and error correction: representation, estimation, and testing, Econometrica, 55, (1987), 251-76. 
[5] R. Haris and R. Sollis, Applied Time Series Modelling and Forecasting, John Wiley and Sons, Ltd., London, 2003.

[6] G. Hondroyiannis, Estimating residential demand for electricity in Greece, Energy Economics, 26, (2004), 319-334.

[7] S. Johansen, Statistical analysis of cointegration vectors, Journal of Economic Dynamics and Control, 12, (1988), 231-254.

[8] S. Johansen, Estimation and hypothesis testing of cointegrating vectors in Gaussian vector autoregressive models, Econometrica, 59, (1991), $1551-1580$.

[9] D. Kwiatkowski, P.C.B. Phillips, P. Schmidt and Y. Shin, Testing the Null Hypothesis of Stationarity against the Alternative of a Unit Root: How Sure are We that the Economic Time Series Have a Unit Root?, Journal of Econometrics, 54, (1992), 159-178.

[10] T. Moursi and M. El-Mossallamy, Forecasting Key Macroeconomic variables: A pilot study. Paper presented to the Ministry of Planning, Cairo, Egypt, 2003.

[11] National Energy Efficiency Program (NEEP), http://www.neep.org.sa.

[12] M.H. Pesaran, The Role of Economic Theory in Modelling the Long Run, The Economic Journal, 107, (1997), 178-191.

[13] P.C.B. Phillips and S.N. Durlauf, Multiple time series regression with integrated processes, Review of Economic Studies, 53, (1986), 473-495.

[14] P.C.B. Phillips and P. Perron, Testing for a unit root in time series regression, Biometrika, 75, (1988), 335-346.

[15] R.S. Pindyck and D.L. Rubinfeld, Econometric models and Economic Forecasts, (4th ed.). Boston, Mass.: Irwin/McGraw-Hill, 1998.

[16] Saudi Arabian Monetary Agency (SAMA), Annual Report, (2010), http://www.sama.gov.sa/ReportsStatistics/Pages/AnnualReport.aspx.

[17] C. Sims, Macroeconomics and reality, Econometrica, 48, (1980), 1-48.

[18] US. Energy Information Administration (EIA), 
http://www.eia.doe.gov/emeu/cabs/Saudi_Arabia/pdf.pdf

[19] World Bank (http://data.worldbank.org/indicator/).

\section{Appendix (A)}

Table (A.1): Energy and economic data (1982-2007)

\begin{tabular}{|c|c|c|c|}
\hline Period & $\begin{array}{c}\text { ENERG } \\
\text { (thousand kilo ton of } \\
\text { oil equivalent) }\end{array}$ & $\begin{array}{c}\text { RGDP } \\
(1999=100) \\
\text { (Billion } \\
\text { Riyal) } \\
\end{array}$ & $\begin{array}{c}\text { CPIENERG } \\
(1999=100)\end{array}$ \\
\hline 1982 & 47.32 & 476.928 & 121.4 \\
\hline 1983 & 51.72 & 437.032 & 123.2 \\
\hline 1984 & 45.464 & 423.101 & 119.6 \\
\hline 1985 & 46.744 & 404.703 & 116 \\
\hline 1986 & 50.547 & 425.147 & 101.9 \\
\hline 1987 & 54.417 & 408.752 & 87.7 \\
\hline 1988 & 62.455 & 437.172 & 81.6 \\
\hline 1989 & 62.296 & 439.224 & 79.7 \\
\hline 1990 & 59.257 & 476.244 & 79.6 \\
\hline 1991 & 70.225 & 521.011 & 83.3 \\
\hline 1992 & 79.201 & 542.714 & 84.4 \\
\hline 1993 & 82.381 & 542.907 & 88.5 \\
\hline 1994 & 86.891 & 547.792 & 93.7 \\
\hline 1995 & 86.942 & 549.983 & 100.6 \\
\hline 1996 & 93.014 & 567.570 & 101.1 \\
\hline 1997 & 92.886 & 582.418 & 100.4 \\
\hline 1998 & 98.839 & 598.122 & 99.9 \\
\hline 1999 & 100.379 & 593.955 & 100 \\
\hline 2000 & 104.877 & 623.218 & 100 \\
\hline 2001 & 109.248 & 629.262 & 100.1 \\
\hline 2002 & 120.94 & 629.775 & 100 \\
\hline 2003 & 121.175 & 678.155 & 100 \\
\hline 2004 & 130.184 & 713.915 & 100.3 \\
\hline 2005 & 138.741 & 753.518 & 100 \\
\hline 2006 & 145.197 & 777.230 & 101 \\
\hline 2007 & 150.326 & 802.989 & 109.2 \\
\hline
\end{tabular}


Table (A.2): Vector Autoregression Estimates

Sample (adjusted): 19822007

Included observations: 26 after adjustments

Standard errors in ( ) \& t-statistics in [ ]

\begin{tabular}{|c|c|c|c|}
\hline & LENERG & LRGDP & LCPIENERG \\
\hline \multirow{4}{*}{ LENERG(-1) } & 0.363674 & -0.102858 & -0.291024 \\
\hline & $(0.22158)$ & (0.13794) & $(0.08272)$ \\
\hline & [ 1.64128] & {$[-0.74568]$} & [-3.51798] \\
\hline & -0.141991 & -0.023607 & 0.107456 \\
\hline \multirow[t]{3}{*}{ LENERG(-2) } & $(0.25115)$ & $(0.15635)$ & $(0.09376)$ \\
\hline & [-0.56537] & [-0.15099] & [ 1.14603] \\
\hline & 0.371878 & 0.205578 & -0.066523 \\
\hline \multirow[t]{3}{*}{ LENERG(-3) } & $(0.16381)$ & $(0.10198)$ & $(0.06116)$ \\
\hline & [ 2.27018] & [ 2.01595] & [-1.08774] \\
\hline & 0.601748 & 0.839838 & -0.082209 \\
\hline \multirow[t]{3}{*}{ LRGDP(-1) } & $(0.25932)$ & $(0.16143)$ & $(0.09682)$ \\
\hline & [ 2.32047] & [ 5.20235] & [-0.84913] \\
\hline & 0.660179 & 0.333423 & 0.261415 \\
\hline \multirow[t]{3}{*}{ LRGDP(-2) } & $(0.35947)$ & $(0.22378)$ & $(0.13421)$ \\
\hline & [ 1.83652] & [ 1.48996] & [ 1.94786$]$ \\
\hline & -0.505500 & -0.282498 & 0.526108 \\
\hline \multirow[t]{3}{*}{ LRGDP(-3) } & $(0.39385)$ & $(0.24518)$ & $(0.14704)$ \\
\hline & [-1.28349] & [-1.15220] & [ 3.57798] \\
\hline & -0.817573 & 0.086580 & 0.778922 \\
\hline \multirow[t]{3}{*}{ LCPIENERG(-1) } & $(0.53659)$ & $(0.33404)$ & $(0.20033)$ \\
\hline & [-1.52363] & [ 0.25919$]$ & [ 3.88813] \\
\hline & 0.762009 & -0.467845 & -0.244940 \\
\hline \multirow[t]{3}{*}{ LCPIENERG(-2) } & $(0.64324)$ & $(0.40043)$ & $(0.24015)$ \\
\hline & [ 1.18464$]$ & [-1.16834] & [-1.01995] \\
\hline & -0.174987 & 0.306783 & -0.107979 \\
\hline \multirow{3}{*}{ LCPIENERG(-3) } & $(0.34584)$ & $(0.21529)$ & $(0.12911)$ \\
\hline & {$[-0.50598]$} & [ 1.42497] & {$[-0.83631]$} \\
\hline & 1.633394 & 0.216423 & 2.554545 \\
\hline \multirow[t]{2}{*}{$\mathrm{C}$} & (1.23434) & $(0.76840)$ & $(0.46083)$ \\
\hline & [ 1.32330$]$ & [ 0.28165$]$ & [ 5.54337] \\
\hline R-squared & 0.990732 & 0.987796 & 0.987710 \\
\hline Adj. R-squared & 0.985518 & 0.980931 & 0.980797 \\
\hline Sum sq. resids & 0.033411 & 0.012948 & 0.004657 \\
\hline S.E. equation & 0.045697 & 0.028447 & 0.017060 \\
\hline F-statistic & 190.0363 & 143.8886 & 142.8734 \\
\hline Log likelihood & 49.64825 & 61.97153 & 75.26504 \\
\hline Akaike AIC & -3.049865 & -3.997810 & -5.020387 \\
\hline Schwarz SC & -2.565982 & -3.513927 & -4.536504 \\
\hline Mean dependent & 4.411350 & 1.703790 & 4.587533 \\
\hline S.D. dependent & 0.379730 & 0.206002 & 0.123112 \\
\hline \multicolumn{2}{|c|}{ Determinant resid covariance (dof adj.) } & $4.34 \mathrm{E}-10$ & \\
\hline \multicolumn{2}{|c|}{ Determinant resid covariance } & $1.01 \mathrm{E}-10$ & \\
\hline \multicolumn{2}{|c|}{ Log likelihood } & 188.5036 & \\
\hline \multicolumn{2}{|c|}{ Akaike information criterion } & -12.19259 & \\
\hline \multicolumn{2}{|c|}{ Schwarz criterion } & -10.74094 & \\
\hline
\end{tabular}


Table (A.3) VAR Residual Portmanteau Tests for Autocorrelations

VAR Residual Portmanteau Tests for Autocorrelations

H0: no residual autocorrelations up to lag $h$

Date: 05/23/11 Time: 20:58

Sample: 19822007

Included observations: 26

\begin{tabular}{cccccc}
\hline Lags & Q-Stat & Prob. & Adj Q-Stat & Prob. & df \\
\hline 1 & 5.898415 & NA* & 6.134352 & NA* $^{*}$ & NA* $^{*}$ \\
2 & 20.53638 & NA* & 21.99215 & NA* $^{*}$ & NA $^{*}$ \\
3 & 30.51740 & NA* & 33.27504 & NA* $^{*}$ & NA $^{*}$ \\
4 & 38.32110 & 0.0000 & 42.49760 & 0.0000 & 9 \\
\hline
\end{tabular}

*The test is valid only for lags larger than the VAR lag order.

$\mathrm{df}$ is degrees of freedom for (approximate) chi-square distribution

Table (A.4) VAR Residual Normality Tests

VAR Residual Normality Tests

Orthogonalization: Cholesky (Lutkepohl)

H0: residuals are multivariate normal

Date: 05/23/11 Time: 21:12

Sample: 19822007

\begin{tabular}{ccccc}
\hline Component & Skewness & Chi-sq & df & Prob. \\
\hline 1 & -0.196589 & 0.167472 & 1 & 0.6824 \\
2 & -0.031997 & 0.004437 & 1 & 0.9469 \\
3 & -0.185311 & 0.148807 & 1 & 0.6997 \\
Joint & & 0.320715 & 3 & 0.9561 \\
\hline & & & & \\
\hline Component & Kurtosis & Chi-sq & df & Prob. \\
\hline 1 & 1.297994 & 3.138228 & 1 & 0.0765 \\
2 & 0.906201 & 4.749326 & 1 & 0.0293 \\
3 & 0.954797 & 4.531426 & 1 & 0.0333 \\
Joint & & 12.41898 & 3 & 0.0061 \\
\hline \multicolumn{6}{c}{} & & & \\
\hline Component & Jarque-Bera & df & Prob. & \\
\hline 1 & 3.305699 & 2 & 0.1915 & \\
3 & 4.753763 & 2 & 0.0928 & \\
Joint & 4.680233 & 2 & 0.0963 & \\
\hline
\end{tabular}




\section{Appendix (B)}
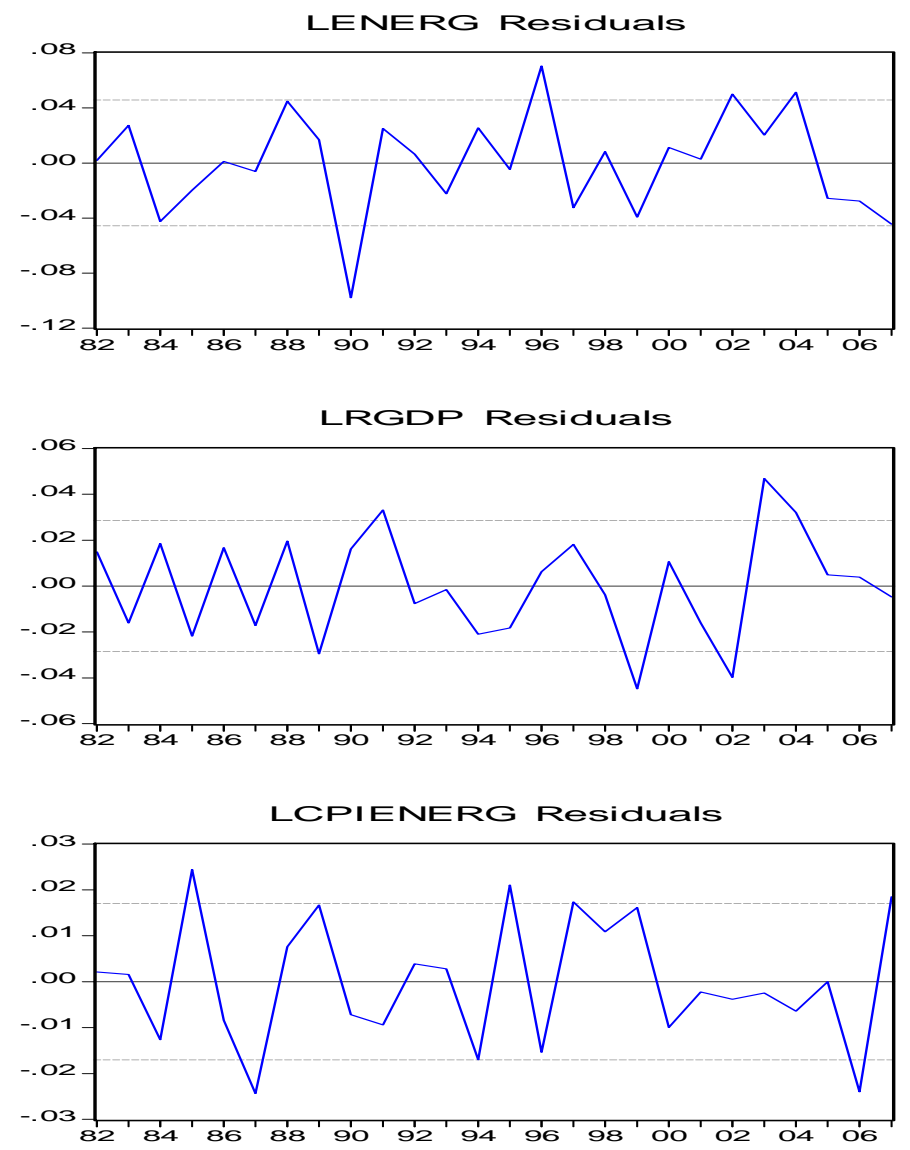

Figure (B.1) the residuals of VAR equations 
Autocorrelations with 2 Std.Err. Bounds

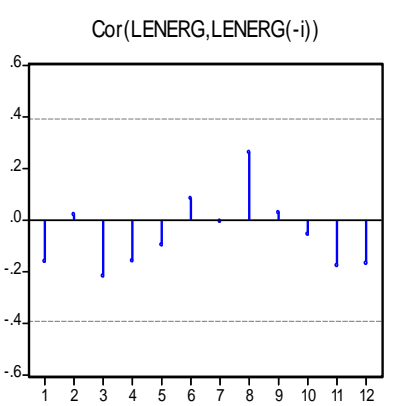

$\operatorname{Cor}($ LENERG,LRGDP(-i))

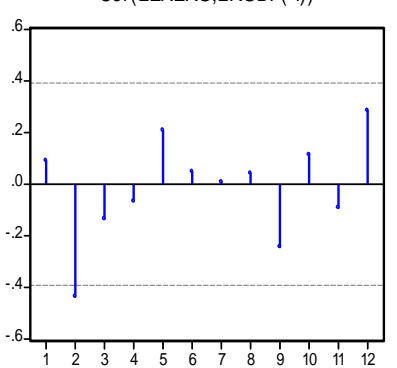

$\operatorname{Cor}(\operatorname{LRGDP}, \mathrm{LRGDP}(-\mathrm{i}))$

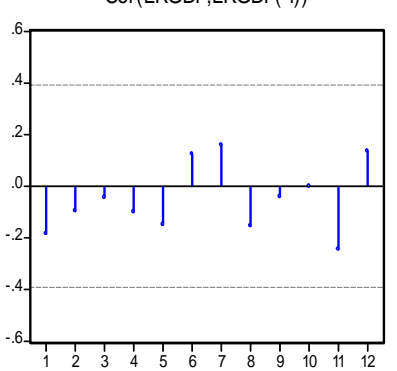

$\operatorname{Cor}($ LCPIENERG,LRGDP(-i))

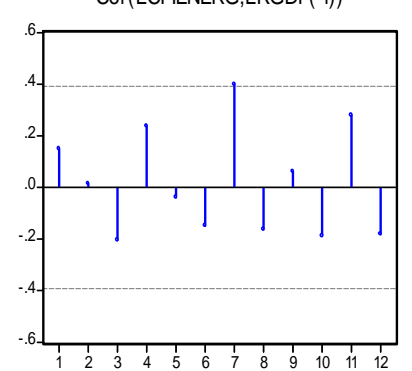

Cor(LENERG,LCPIENERG(-i))

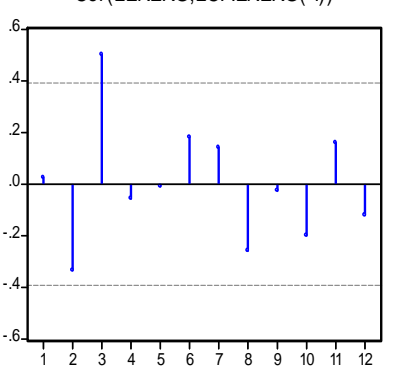

Cor(LRGDP,LCPIENERG(-i))

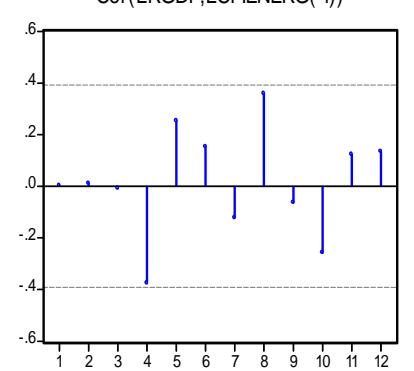

Cor(LCPIENERG,LCPIENERG(-i))

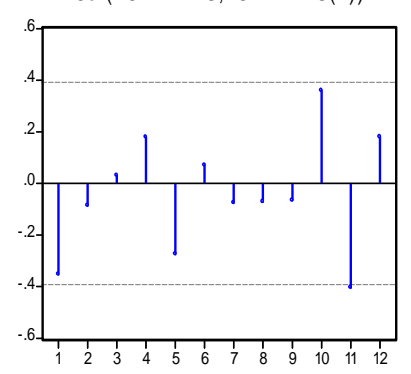

Figure (B.2) Autocorrelation correlogram 